\title{
Discussions on the Artistic Features and Singing Styles of the French Art Songs
}

\author{
Chunli Ruan ${ }^{1}$ \\ ${ }^{1}$ College of Art, Xiamen University, Xiamen Fujian 361005, China \\ ${ }^{a}$ email,
}

Keywords: Discussions, Artistic Features, Singing Styles, French Art Songs

\begin{abstract}
The European music in the nineteenth century represents the most popular period of romanticism. The innumerable musiciansmade heartfelt endeavors to compose their music to have the unprecedented development of the romantic music and various musical genres insin the nineteenth century become possible. Art songs, as a type of concert solo songs with more refined and perfect composition, was also developed in parallel with the romantic poetry under the influence ofromanticismin this period and eventually was considered as a type of romantic expression. It can be said that the development and perfection of romantic art songs is a great achievement made with most attentions attracted during the whole romantic music period. In the development of vocal music art, art songs playedas an important position. As an important part of vocal music art, art songshad a great and significant influence on the vocal music art. French art songs are representedthe popular songs in the late 30 years of the nineteenth century and are hereby known as the "chanson" or " mélode". French art songs, as one of the genres of the various world art songs, has made very brilliantachievements. This paper, starting from the emergence and development of the French art songs, provides discusses on the technical requirements and singing principles of the French art songsand demonstrates the author's viewpoint for the "second creation" of the vocal performance under the aesthetic principles of "authenticity and creativity" plus "skills and performance."
\end{abstract}

\section{The Emergence and Development of the French Art Songs}

Songs in France enjoy a long history. In the romantic period of France, the rich and colorful folk songs and the singer's courtly music were developed at an earlier stage. No matter in the era of the Middle Ages of the papacy, or in the liberation of humanity brought to France by the dawn of humanism, the various secular and religious vocal music genres have never been preventedfrom further growth and reproduction. In the middle of the sixteenth century, there was aria with solo lute accompaniment in France, which was well known as Chanson. At the beginning of the seventeenth century, homophony and sound were introduced from Italy and the Romanza was hereby developed in a prompt way. With the dissemination of the poets' singing, the aria with the lute, guitar and harpsichord accompaniment was developed. The music at that time had diversified types, including the delicate love songs of the royal court, the shepherd's pastoral songs and lyrics, the romantic and narrative songs with a long history for the singing poets, the popular songs, the dancing music, drinking songs and the simple, easy and pleasant songs, as well asthe political and satirical songs. In the eighteenth century, the "chamber cantata” genre was introduced from Italy and Rameau created the famous "Orpheus.” Also, Couperin created arias. During the French Revolution at the end of the eighteenth century, a large number of the outstanding revolutionary songs and patriotic songs were created. The middle of the nineteenth century to the early twentieth century was whenFrench art songs were born, developed and thrived. In the second half of the nineteenth century, poetry of symbolic poets like Baudelaire, Verlaine, Malarmé and others were considered as the catalyzer for the birth and growth of the art songs as a music genre in France. It was these secret poems with focus put on rhetoric, syllable, melodious perceptionwith extreme attention paid, clear and hazy combination emphasized for expressing personal inner elusive, that not only provided the diction basis for such delicate vocal music genre, but also established the French art songs featured 
aselegant and delicate, with more intimation than direct narration and more connotation than passion. The verse of the symbolic poetry has a different length, which made the art songs break through the romanza and ideologism to have the musicians granted with great freedom for music creations.

Niedermeier, the main forerunner of art song, adopted some romantic poetry and broke through the old model of romantic music. However, the real beginning of the French art song should be started fromBerlioz, whose works were named "melodie"to differentiate from the German art song and those songs which were under the concept that "melody is everything." Songscreated by Berlioz broke through the standard creation of the early French chanson'ssymmetrical structure and strophic form, with piano accompaniment given independence and expressive force. After Berlioz, many other French composers such as Meyerbeer, Gounod, Bizet, Delibes, and Massenet also created many outstanding art songs and made their own contributions to the development of the French art song. Until the second half of the nineteenth century, Fauré, Duparc, Debussy and other French composersshowed their own styles, which were different from each other's but within the French temperament. These advancedthe French art songs' development to the most prosperous period. Till then, the French art song had completely broke away from the influence of the German art song and became a unique art songs with French style.

\section{Technical Requirement for Singing the French Art Song}

Singing the French art song is totally different from singing other art songs or operas. However, the technical requirements remain the same. as BEL CANTO technique is mainly applied. The classical viewpoint for BEL CANTO is the breath, on which support and application are much emphasized. Singing with the breath support is an important rule for BEL CANTO technique (1); each momentsinging must be conducted with the correct breath support.

The beginning sound. The proper'onset' sound includes the correct breath support and proper throat coordination. The beginning sound should be light, bright, soft and round. It is the basis to obtain a good singing effect and is the most basic means to adjust the breath, throat status and concentrated resonance. If the tongue root and throat are lowered too much, the glottis will be opened too far, then theattack will show clumsy status with glide portamento. If prominentia laryngea is raised too high, the voice will be squeezed and choked. Although the timbre is bright, the breath is not smooth, the sound becomes narrow and small with dry breath. If breath is rushed toomuch, the beginning sound willbe rough and stiff. If the breath support is not strong enough; hence, the sound becomes weak and lacks luster.Only with appropriate collaboration among the throat, tongue, breath and other physical components, can the accurate beginningsound be made accordingly.

The unity of the sound area. Caccini, the founder of BEL CANTO, believes that man has two sound areas, namely the thoracic sound area and head voice area (also called the true voice and virtual sound). Any singer, with a good command of singing skills, has a clear divide for the acoustic area; besides, the cracking sound, timbre and tone volume disunity will easily occur. For BEL CANTO teaching, the most important goal is to unify the upper and lower sounds as a same sound.

Legato. For BEL CANTO, it is required that the singing melody and lines should be similar to those made by a violin or flute. They should be accurate, relaxed, coherent, free. The breath control should be similar to that made by a violin and should be steady, smooth and flexible. If there is no legato, there is no melodic line and beautiful singing under the BEL CANTO concept.

Soundvolume control. For BEL CANTO, emphasis is put on sound volume controlling by breath, which is able to make the sound stronger or lower, and is also able to make various sound volumes according to different emotions.

The beautiful sound. For BEL CANTO, the most valuable feature is its plumpness and brightness, with metal color and relaxed and mellow sound quality, which includes multiple overtones with mellow timbre. In addition, it also has sufficient resonance with abundant sound. 
The above are not only the major viewpoints for the BEL CANTO school of thought, but also the main technical aesthetic standards of the art song and operatic music. In singing the French art song, the above points of view have been fully reflected. However, these ideas may have different aesthetic standards in a specific art practice according to different forms of performance. The following paragraphs will be focused on the discussion of the singing principle of the French art song based on the differences of the aesthetic principles of the vocal performance, the singing principles of art song and operatic singing.

\section{The Singing Principle of the French Art Song}

The Aesthetic Principles of Vocal Performance. Vocal performance is regarded as the "secondary creation," it is the re-creation of art based on the "initial creation" - the composition. In art practices, a certain aesthetic principle should be followed. Vocal music creates the image of music through the sound, so as to show a certain degree of emotion that meets the listener's aesthetic needs for the auditory and visual arts from multiple aspects. The musical image created by the vocal art belongs firstly to the category of musical composition; it is the purpose of musical creation. Vocal performance, by the achievements of the composition - namely the performance of musical works creates the musical image, which is called the secondary creation, where the essence and significance is that it is not only needed to faithfully reflect the original works, but also needs to supplement and enrich the original works by the creative performance, so that the musical works can radiate with new luster. The secondary creation of vocal music performance actually brings vitality to the musical works. This is conducted based on the creation of the initial composition, which must be used as the starting and destination points for the secondary creation.

\section{Faithful reproduction}

(1) Reproduction of original works. As a singer, one needs to pay attention to whether the composer has expressed the life of the text with its contemporary spirit. From an artistic point of view, the aesthetic is a reflection of effectiveness (1), and the realistic reproduction of life succeeds in reflecting the aesthetics. In this sense, it can be said that if there is no real reproduction, there will be no successful performance. Thus, a singer - the main instrument for the composition - should faithfully reproduce the objective life described by the poet as a priority during the secondary creation once he or she chooses a specific songwriter's work and identifies with it, so as to have the performance become a living organism. The singer needs to use realistic approach to create a real and expressive musical image that properly reflects the reproduction and representation of the musical work created initially. It is not advisable to randomly misrepresent or violate the author's aspiration. Wagner has even raised this question: He believed that the expression of the content of a musical work to the audience is of paramount significance. In fact, a composer writes the sound on paper, and the sound should be expressed through the singer with the imagination and the effect the composer conferred. Wagner wrote that the values of all the players are entirely dependent on the maintenance of the values of the artistic creation. If the performer's purpose is only to show off their skills, that means they will give up their own personality (2). Although what Wagner talked about is for the player, I think it is also suitable for the singers we've discussed in this paper. We should firstly explore and understand the composer's intention. Lister wrote that a singer's intensive study of the work during the preparation stage is extremely important (3). However, we mustunderstand the works in order to not result in a merely mechanical singing performance with no personal creation.

(2) Reproduction of history. Any musical work is the product of a particular historical period, and it is bound to have a specific musical style of that period. To grasp the work's true style from the historical point of view and to achieve this true style, a singer needs to be familiar with and feel the poets's and composer's environments, so that a more realistic performance of the work with the historical style can be reflected. For example, the singing of the artistic song created by Fauré has a 
totally different style from that of Schumann'sWomen's Love and Life since these two composers were born in different times with different backgrounds and living environments. Thus, the styles of the works are different. This requires that a singer show their respective singing styles according to the different historical backgrounds and environments.

\section{Abundant creativity}

For vocal performance - a secondary creation- it is not sufficient to only reflect faithfully the original works. If a singer only sings the music in accordance with the given score, this may reduce the value of the vocal performance art. It must be combined with the singer's creation to achieve a unity of reality and creativity in combination with the historical era, so as to perfectlycomplete the artistic mission of vocal performance.

(1) Combination of reality and creation. Singers should have their own understanding of the musical works, which shall not only comply with the basic concept of the original work, but also display the passion, intelligence, talent and personality of the singer. Under the premise that the concept of the original work is abided by, different singers may show different style of the same work, as they are born in different times and social environments and with their own life experiences and personality, which may be potentially involved and reflected in their singing. There is no doubt that the musical performance creation requires such personal development. The significance lies in the deep reflection of the works and the emotional meanings instead of the superficial meanings or emotions reflected by the singers. The musical sound may be transmitted to the limited space, while the meanings are limitless, with boundless musical images included and extended beyond the works.

(2) The unity of history and the era. In the reproduction of any style of vocal music, it is inevitable to understand it in more that one way, as we cannot help understanding works created in the past through our contemporary attitudes. Performers cannot completely neglect their own times, and they also consciously stand in their own position with contemporary perspective to observe the historical phenomenon. The spirit of the times and the aesthetic ideas of the performer will certainly affect reflection and treatment of the historical works. In the new era, performers stand in the position of their times, explain and perform the works in different ways and bring a new vitality to the historical works. This tends to brush off the dust of history, to explore the positive factors and modern standards of beauty that have never been discovered in the historical works, and enrich and supplement accordingly with the new spirit of the times and aesthetic tastes. We shall avoid the historical style that completely ignores the works' content and one-sided emphasis on the modernization of the musical performance, or just stick to the works with historical style and completely reject the spirit of the times with extreme views and practices. Today, when we sing the works of Schubert, Fauré and others we should, first of all, take into account the works of the era and the singing styles combined with elements of their own times to complement and enrich the music so as to create pieces with continuously new elements.

\section{Unity of Skills and Performance}

For vocal music performance arts, skills and performance are extremely important. I think that the skill and the performance are the sound and emotion respectively, the relationship between them is harmonious and indivisible; thus, it is also to sing wonderfully with a silver voice and deep feeling. As a vocal performer, the sound is a must. Stanislavski once requested of the singer that their singing should be so perfect that audiences become intoxicated with it. Only can a solid technique can they have the ability for the performance and adaptability, without limitation of a solid technique. Without the burden of sound, it is possible to perform the music with heartfelt feelings and soul. If a singer's singing skills are not qualified, how can he be able to consider his music performance? If he has to think about breath control, the proper location for breathing, the location of throat or the other concerns, it will notbe possible for him to take care of the works of music, not to convey the style, especially in singing the art song, where strict technical requirements are set for 
a singer. The aesthetic standards of art song are greatly different from those of opera. Opera requires great sound volume and a sonorous beauty. Thus, a singer's vocal condition is very important. In fact, a singer with great sound volume but lower sound techniques has more advantages than those who have high music accomplishment but lower sound volume. This is due to the different aesthetic standards between art song and opera singing. In singing art song, soft or gentle beauty is emphasized instead of volume, together with the musicality, beautiful sound and flexible technique. In the vocal performance arts, the outstanding performance skill and the perfect performance of the arts are mutually complementary to each other. No performance skills, no artistic performance. On the contrary, without an artistic performance, the performance skills will lose their value accordingly. The superb technique fully integrated into the profound artistic performance to truly unify them perfectly, can the aesthetic pleasure be brought to the audience with rich spiritual connotation and emotional expression to affect people.

In general, a singer, as the main body for the secondary creation of vocal performance art, can only create vocal performance art with unique charm when he combines reality and creation as a unity and integrates skills with performance as a whole.

The Singing Principle of the French Art Songs. Schwarzkopf, the German recent famous singer, has even said that the singing of opera is like using a large brush for painting, and singing the art song is like a painting with fine brushwork, which requires careful painting with a very fine pen. This fully illustrated the big differences between singing opera and art song. Singing art song is focused on intimate pleasure; it is the vocal music genre in a concert, employing piano accompaniment instead of the largeorchestral accompaniment needed by opera. Therefore, great volume is not as necessary as in opera singing, which requires great and strong volume contrast. However, singing art song focuses on tone changes and never shows off the superficial effect of sound only. Opera is based on the dramatic conflict for its musical development. Hence, a singer should focus on the sound, dramatic performance and passion. The art song lyrics are adopted from poems created by famous poets. In order to show the quiet, delicate and romantic poetry and style with emotion, the lyric is expressed often with a light voice and mezza voce with crescendos and diminuendos in the higher range. If the opera singing style is considered as strong and magnificent, the singing style of art song is implicit in a soft and gentle focused beauty. Opera performance may require scenery, lighting, costumes, props, posture, gesture and supporting characters to obtain a dramatic effect, so as to move the audience with the sound and performance. However, in the concert, singing the art song only requires a piano accompaniment. The singing uses music, language and voice control to reflect the pieces, and the audience's attention is entirely on the singer's sound performance. Thus, it is necessary for the singer to have perfect intonation, rhythm, piano accompaniment and deep sense of music that complies with the sound texture within narrow range of emotion. Besides, it requires a delicate description of the inner feelings of the characters. The rhythm and emotional change of the art song are smaller than that of the opera aria, and the markings in the musical score require that the singer reflect accurately and delicately through tempo, timbre, volume, rhythm and other aspects.

\section{National Character Traits}

The French nature for the beauty reflected in the music performance is the pursuit of music's beauty in form, a gentle coherent sound, colorful effects, vaguefeelings, accurate intonation, elegant rhythm and melodious lines in order to obtain a pure music aesthetic. The French people are not keen on over-exaggeration; instead, they prefer the simple and diverse structure and form to express exquisite and implicit feelings. French art songs are concise and elegant; they exactly reflect the nation's character. French poets and composers only suggest artistic conceptions, states of mind, hints, impressions or symbolic and unclear feelings or slight melancholy in music which seldom shows romantic fanaticism or emotional outbreaks. Therefore, vocal control needsto have restraint with natural smoothness, as well as implicit purity and strength. The fundamental point is to master a sense of propriety. To pay attention to its rhythm and to not randomly make changesaccording to personal preferences in passages where the composer doesn't give clear indications, or to just show 
off vocal skill (1). The prolonged sound made by random creation should be avoided completely. In addition, singing the coherent phrase must be kept with consistency to avoid portamento. The entire song and phrasing structure must also be accurate to demonstrate perfect singing art.

\section{Conclusion}

The art song of different eras or different ethnic groups usually clearly reflects the theme of the times and the nation's emotion, cultural tradition, or style. In Italy and Spain, musical works are ebullient. In Germany works are rigorous and meticulous. In France works are romantic. In Nordic nations works are pure and fresh. In Russia works are grand and generous. All of these styles and characteristics have been reflected completely in their melody. Compared with the enthusiasm from Italy, the French nation seems to be more romantic. Most probably, it is the nation in the world since ancient times that knows how to enjoy life completely. French songs are romantic and elegant in character. By comparison, they are not as exaggerated and passionate with great emotional fluctuations as Italian songs; they are also not too similar to the German songs that have deep introversion and more thinking than emotional expression. The French song is often focused on lyric melody, gentle rhythm and beautiful lines. The French art song is full of typical French spirit and thoroughly reflects their unique national romantic emotions, and a noble temperament. We can not only feel the romantic feelings through the French art songs, but also feel a unique music language. From the rhythm, harmony and form, their uniquely romantic and exquisite nobility and their elegance is reflected entirely. They are also distinct from the strictness and profundity of Germanic nations. In artistic practice, definite singing principles should be followed.

\section{Reference documentation}

[1] World art and aesthetics, Fifth Edition [M]. Editorial Board of China Art Research Institute of Foreign Literature Institute for World Art and Aesthetics, Published by Art and Culture Publishing House.

[2] Wagner Selection [M].in 1978, Russian Edition.

[3] Liszt Anthology[M].Russian Edition.

[4] By Zhou Tongfang, Faure and French Art Songs[M]. Full Music Spectrum Press.

[5] By Zheng Xiuling, The art of singer. University Music Series[M], Published by Tian Tong Press.

[6] By Liu Zhiming, Western Music History and Style[M].Published by Continental Press.

[7] By Shang Jiaxiang, European Vocal Music Development History [M]. Published by Shanghai Bookstore Publishing House (Hong Kong).

[8] By Zhao Meibo, The Singing Art, [M]. Published by Shanghai Musical Press.

[9] Edited by the Editorial Department of the People's Music Publishing House; compiled with music dictionary entries; Western Music Styles and Genres [M]. People’s Music Publishing House.

[10] Compiling Department of Central Conservatory of Music, translated by Compiling Department of Shanghai Conservatory Of Music. Selected translations from the great encyclopedia of the Soviet Union[M].Music Cultures in Different Countries. Music Publishing House.

[11] [England] Written by Gernald Abraham and translated by Gu Ben; revised by Qian Renkang and Yang Yandi; The Concise Oxford History of Music [M]. Shanghai Music Publishing.

[12] [America]Translated by Paul, Henry, Lange and Zhang Hongdao. Western music culture history in Nineteenth Century [M].People's Music Publishing House. 